\title{
Mutations in Reelin pathway are associated with abnormal expression of microglial IgG FC receptors in the cerebellar cortex
}

Hassan Marzban ( $\sim$ Hassan.Marzban@umanitoba.ca )

University of Manitoba Faculty of Health Sciences

Maryam Rahimi-Balaei

University of Manitoba Faculty of Health Sciences

Xiaodan Jiao

University of Manitoba Faculty of Health Sciences

Azadeh Dalvand

University of Manitoba Faculty of Health Sciences

Shahin Shabanipour

University of Manitoba Faculty of Health Sciences

Shayan Amiri

University of Manitoba Faculty of Health Sciences

\section{Seung H Chung}

University of Illinois at Chicago College of Medicine

Jiming Kong

University of Manitoba Faculty of Health Sciences

\section{Research article}

Keywords: reelin, Purkinje cells, cerebellum, microglia, IgG FC receptors, mice

Posted Date: March 18th, 2020

DOI: https://doi.org/10.21203/rs.3.rs-17697/v1

License: (1) (1) This work is licensed under a Creative Commons Attribution 4.0 International License. Read Full License 


\section{Abstract}

Introduction: Microglia are the immune cells of the central nervous system that are involved in a variety of developmental processes such as regulation of cell death and survival, spatial patterning, and contribute to the development of Purkinje cells during migration. Microglia express immunoglobulin G Fc receptors (FcgRs).

Hypothesis: In this report, we describe microglial FcgR expression in the cerebellum during development related to abnormal Purkinje cell migration.

Method: To detect microglial FcgR, the direct anti-lgG (secondary antisera) and high concentrations of Triton X-100 were applied as a method for labeling microglial cells without the use of any specific primary antiserum. By using the Acp2 -/- mice, which show an excessive Purkinje cell migration into the molecular layer combined with the different knockout mice altering the Reelin pathway (Reeler, Scrambler, and Apoer 2 -/- mice), that Purkinje cells are ectopically located in white matter.

Result: We show the expression of microglial FcgRs in the cerebellum of these mice is absent, but not in the Acp2 -/- mice .

Discussion: These results suggest a role for FcgRs in reelin signaling pathway, not related to Purkinje cell migration, but may be an adaptation to the environment with the large number of ectopic Purkinje cells.

Conclusion: However, the exact correlation between the ectopic Purkinje cells presence and FcgRs absence in reeler, Scrambler, Apoer -/- mice and the presence of FcgRs in Acp2 -/- mutant are yet to be determined.

\section{Introduction}

Purkinje cells (PCs) are the main output of cerebellar cortex and contribute to a variety of cerebellar functions such as coordination and motor learning (1). Following mitotic division at embryonic day (E) 10.5-12.5, PCs start the migration and form the PC plate, which is a multilayer structure made of PCs in the mantle zone (2). The migration of PCs during cerebellar development happens under tightly controlled conditions and the Reelin pathway plays an important role during this process (3). Reelin is a large protein secreted by the granule cell precursors and cerebellar nuclei neurons in the external germinal zone and cerebellar nuclei, respectively (4). Reelin binds to VLDLR (very low-density lipoprotein receptor) and ApoER2 (apolipoprotein-E receptor 2), and activates a protein known as Dab1 (Disabled 1). Dab1 is an adaptor protein essential for the intracellular transduction of Reelin signaling and regulates the migration and differentiation of post-mitotic neurons during brain development $(3,5)$. Evidence showed that mutations in Reelin, Dab1, Apoer2, and Vldlrgenes result in the lack of dispersal of PCs from the cluster and hindered migration of PCs during cerebellar development (6-8). On the other hand, spontaneous mutation in the lysosomal acid phosphatase 2 (Acp2) mouse (nax-naked-ataxia mutant) are associated with excessive migration of PCs to the molecular layer and lack of PCs monolayer formation $(9,10)$. 
Microglia are myeloid-derived cells in the central nervous system (CNS) involved in a variety of developmental processes such as regulation of cell death and survival, spatial patterning, formation and refinement of neural circuits, and synaptic wiring in the CNS $(11,12)$. Evidence indicates that microglia contribute to the development of PCs during migration by controlling the survival and synaptogenesis of these cells $(13,14)$. Microglia express immunoglobulin G Fc receptors (FcgR), which are involved in phagocytic activity, oxidative burst, and inflammatory responses of microglia $(15,16)$. Although recent evidence shed light on the role of mechanisms involved in PCs migration, it is not clear whether abnormal migration is associated with microglial FcgR during cerebellar development.

In this study, we used different knockout mouse models for Reelin pathway (Reeler, Scrambler, and Apoer $2^{\prime-}$ mice) and nax mouse $\left(A c p 2^{\prime-}\right)$, in which PCs migration is decreased and increased, respectively to investigate the expression of microglial FcgRs in the cerebellar cortex of animals during PCs migration.

\section{Materials And Methods}

\section{Animal maintenance and tissue processing}

All animal procedures were performed in accordance with institutional regulations and the Guide to the Care and Use of Experimental Animals from the Canadian Council for Animal Care and has been approved by local authorities "the Bannatyne Campus Animal Care Committee", University of Manitoba Animal Care Committee (ACC), and University of Calgary Animal Care Committee (ACC). Animals were maintained at room temperature and in controlled humidity (50-60\%) with a 12-h light dark cycle. All efforts were made to minimize the number of animals used, and the animals were treated in a humane manner. In this study, we used nax (Acp $2^{-/-}$), Reeler (reelin mutant), SCM (Dab1 mutant), and Apoer (apoE receptor mutant) mice. An Acp $2^{-/-}$colony was established in the Genetic Modeling Center at the Faculty of Health Sciences, University of Manitoba, by breeding mice (C57BL/6) heterozygous for the Acp $2^{-/-}$ mutation (17, 18). Mice null for Reelin (B6C3Fe a/a-Relnrl/J; (19, 20)), Dab1( CBy.129S4-Dab1tm1 Cpr/J; $(21-23)$ ), and Apoer ( B6;129S6-Lrp8tm1Her/J; $(4,8)$ ) were the generous gift of Dr. Richard Hawkes (University of Calgary), which were purchased from The Jackson Laboratory. Wild type littermates were used as controls in all studies. The animals were perfused and post-fixed with $4 \%$ paraformaldehyde and then cryosectioned at $20 \mu \mathrm{m}$ and processed for immunohistochemistry according to methods described in Bailey et al. (18).

\section{Antisera}

We used rabbit polyclonal Anti-Iba1 antibody (Millipore \#MABN92). Iba1 is a 17-kDa EF hand protein that is specifically expressed in macrophages/microglia (24). Biotinylated anti- FcgRs (a-lgGs; secondary antibodies or antisera) can be detected with the $A B C$ method and avidin-bound fluorochromes (Vectastain, Vector Laboratories Inc., Burlingame CA., USA), as we used this method to detect microglia (25). Rabbit anti-GFAP (1:2000 dilution, Chemicon Inc. Temecula U.S.A.) specifically recognizes 
astrocytes. We also used Rabbit polyclonal anti-MBP (Santa Cruz \#sc-13914) and mouse monoclonal anti-Calb1 (26).

\section{Immunohistochemistry}

Peroxidase immunohistochemistry was carried out on cerebellar sections as described previously (17, 27). Briefly, tissue sections were washed thoroughly blocked with $10 \%$ normal goat serum (Jackson Immunoresearch Laboratories, West Grove, PA) and incubated in 0.1M PBS buffer containing $0.1 \%$ Triton$\mathrm{X}$ and the primary antibody for $16-18$ hours at $4{ }^{\circ} \mathrm{C}$. Secondary incubation in horseradish peroxidase (HRP) conjugated goat anti-rabbit or HRP-conjugated goat anti-mouse antibody (diluted 1:200 in PBS; Jackson Immunoresearch Laboratories, West Grove, PA) lasted 2 hrs at room temperature. Diaminobenzidine (DAB, $0.5 \mathrm{mg} / \mathrm{ml})$ was used to visualize the reaction product. Cerebellar sections for double-label fluorescent immunohistochemistry were processed as described previously (27). To detect microglial immunoglobulin G Fc receptors (FcgR), the direct anti-lgG (secondary antisera) and high concentrations of Triton X-100 (1\%) was applied as a method for labeling microglial cells without the use of any specific primary antiserum (25). Biotinylated anti- FcgRs (a-IgGs; secondary antibodies or antisera) can be detected with the avidin-biotin-immunoperoxidase (ABC) method and with avidin-bound fluorochromes. To reveal the secondary antisera binding, the ABC method was used. Biotinylated secondary antisera diluted at 1:200 in PBS and incubated for $2 \mathrm{hr}$. The Vectastain Elite ABCkit (Vector, Burlingame, CA; \#PK-61000) was diluted at 1:200 as well and incubated for $3 \mathrm{hr}$. Tissue-bound peroxidase was revealed by incubating the sections in a solution containing $0.002 \%(\mathrm{w} / \mathrm{v}) 3,3^{\prime}-$ diaminobenzidine(DAB; Sigma, St Louis, MO) and 0.003\% (v/v) $\mathrm{H}_{2} \mathrm{O}_{2}$ in 0.05 M Tris-HCl buffer, pH 7.6. The sections were mounted, dehydrated, and cover slipped with Entellan (Merck; Darmstadt, Germany).

\section{Figure Preparation}

For bright field microscopy, an Olympus BH-2 microscope was used and images were captured using Image-Pro Expression software. For fluorescence microscopy, a Ziess Lumar.V12 stereomicroscope was used to capture images of entire cerebellar sections using AxioVision 4 software. For high magnification fluorescence microscopy a Ziess Z1.Imager with AxioVision 4 software and a Zeiss LSM 700 confocal microscope with Zen software were used to obtain images. Images were cropped, corrected for brightness and contrast, and assembled into montages using Adobe Photoshop CS5 Version 12.

\section{Results}

To visualize the microglia, we utilized biotinylated anti-mouse FcgR secondary antibody by addition of high concentrations of Triton X-100 (1\%) and revealed secondary antibody binding by the avidin-biotinimmunoperoxidase $(A B C)$ method $(25,28)$. Application of this method revealed the non-neuronal cells with branches similar to the microglia in the cerebellar cortex and raises the speculation that FcgRs are localized on microglia (Fig. 1A, D). To confirm that, the ionized calcium binding adaptor molecule 1 (Iba1) 
marker was used to demonstrate the morphological features of microglial cells (29-31). A transverse section of the cerebellum immunostained with Iba1 shows that microglia are the only immuno-reactive cells with this marker and the morphology closely resemble the FcgRs ${ }^{+}$cells. (Fig. 1B, C). Double immunostaining confirmed that FcgRs are co-labeled with the Iba1 (Fig. 1F). The detail of co-localization of FcgR and Iba1 immunostaining is demonstrated in higher magnification (Fig. 1D-F). Positive microglial cell appeared to contain FcgR-like immunoreactivity.

To determine whether FcgR is expressed in other non-neuronal cells, the wt cerebellar sections were stained by double-fluorescence immunohistochemistry, FcgRs -like immunoreactivity was not colocalized in GFAP-positive astrocytes (Fig. 2A-C) and in MBP-positive oligodendrocytes (Fig. 2D-F).

To understand the expression of FcgRs during the development of the microglia, the cerebellar sections were used during perinatal development. FcgRs immunoreactivity is distinguishable at prenatal stages of development and by E17, FcgR immunoreactivity is weak at the core of the cerebellar sections in developing white matter (Fig. 3A, B). The FcgR immunoreactivity is strong in microglial precursor cells which are located in developing white matter at around P1 (Fig. 3C) and P3 (Fig. 3D). By P10, developing microglial cells with their extended process are clearly detectable by FcgRs which are highly populated in the white matter and indicated stream migratory pathway to cerebellar cortex (Fig. 3E, F).

To determine whether FcgRs expression profile is altered in the cerebellum with PCs migration disorders, we used nax mutant cerebellum which shows an excessive PC migration and compared it with other Reelin mutant mice cerebellum with prominent ectopic PCs in white matter and lack of PCs cluster dispersal.

The cerebellar cortex of nax mouse is abnormal and three layer of the cortex is indistinguishable with PCs invading the molecular layer and significantly reduce in the number of granule cells ((18) and Fig. 4). In a P17 wt mouse, the PCs bodies almost form a monolayer while their dendrite extension is apparent in developing molecular layer and directed toward the pial surface (Fig. 4A) while, in nax cerebellum PC bodies with less dendritic arborization and form a multilayer of the cells instead of a monolayer in cortex (Fig. 4D). Multilayer PCs occupy all molecular layer and their dendrites are branched in multidirectional pattern in nax cerebellum (Fig. 4D) in comparison to the wt (Fig. 4A). Recently we have shown the distribution of both ramified and activated microglial cells in nax cerebellum compared to the wt siblings cerebellum (32). In spite of the activated microglia, the FcgR expression in microglia of the nax cerebellum with excessive PCs migration which were detected by lba1 at P17 were colocalized, which is similar to the wt cerebellum (Fig. 4B, E; higher magnification in Fig. 4C,F). To determine the FcgR expression profile in cerebellar with ectopic Pcs in white matter, FcgR and lba1 immunopeoxidase staining performed using the scm cerebellum (Fig. 5). Surprisingly, no FcgR immunoractivity was observed in scm cerebellum (Fig. 5D, E) compare to scm wt cerebellum (Fig. 5A, B, C). Iba1 immunostaining was utilized to determine whether the lack of immunoractivity in FcgRs is due to the lack of microglia in cerebellum. Results revealed the existence of ramified microglia and they are not activated in respond to ectopic neuronal environment (Fig. 5F, G). To test the hypotheis that FcgR expression is 
absent in scm pathway, we have pursued in Reeler and $\mathrm{Apoer}^{-/-}$mutants. Double immunoflouresent staining using anti- FcgR and Iba1 antibodies (Fig. 6) in reeler wt confirmed the colocalizrtion of the FcgR and Iba1 (Fig. 6A-C). However, double immunoflouresent staining using anti- FcgR and Iba1 antibodies in reeler (Fig. 6D-F), Apoer ${ }^{-/-}$(Fig. 6G-I), and scm (Fig. 6J-L) mutants revealed lack of FcgR expression on their microglia despite their well-organized Iba 1 immunopositve microglia when compared with control wt (Fig. 6A-C).

\section{Discussion}

In the current work, we found that cerebellar microglia express FcgRs during development starting at E17 until postnatal stage at P10. We also found that there is an increase in the expression of microglial FcgRs at the postnatal stage in the cerebellum in comparison with that of the prenatal stage. Previous studies have shown that FcgRs are expressed in a variety of cell types in the brain during adulthood (16), but there are few studies about the role and expression of FcgRs during gestational period and early development (33). Also, we showed that cerebellar astrocytes do not express FcgRs. This report is consistent with a previous study, which showed astrocytes in the cerebellum do not express FcgRs (34). Although there are few evidence on the expression of FcgRs on the cerebellar microglia during gestational period, but our data showed that FcgRs are expressed on cerebellar microglia suggesting their involvement in cerebellar development. It has been shown that the numbers of microglia increase progressively during cerebellar development (E11.5) until postnatal period (35). In addition, evidence indicates that programmed cell death plays an important role in the brain development $(36,37)$, and microglia are responsible for the phagocytosis of neurons following apoptosis in order to clear pathways for developing cortical afferents and efferents during cerebellar development $(14,35,38)$. It is important to note that FcgRs are essential for the phagocytic activity of microglia, and increased expression of FcgRs on cerebellar microglia in our study is associated with the increased number of microglia during development $(39,40)$.

Further, we showed that manipulation of the Reelin pathway is associated with the lack of dispersal of PCs from the cluster and hindered migration of PCs during cerebellar development. In this context, previous studies have shown that reeler mice (mutation in the Reln gene), scrambler mice (mutation in the Dab1 gene), and Apoer2 ${ }^{-/-}$mice exhibit ectopic PCs and impairments in PCs migration (6-8). On the other hand, nax mice (mutation in the Acp2 gene) showed excessive migration of PCs to the molecular layer and lack of PCs monolayer formation. In this study, our observation in both Reelin pathway manipulated mice and nax mice cerebellum suggests that that microglia are present in the cerebellum of all animals and decreased or increased PCs migration has no effect on Iba 1 expression. Interestingly, unlike nax mice, reeler, scrambler, and Apoe ${ }^{-/-}$mice had no expression of FcgRs on their microglia. Our results revealed that manipulations in Reelin pathway affected the expression of microglial FcgRs in the cerebellum. Previous studies demonstrated that manipulation of Reelin signaling directly changes radial glia morphology and biochemical maturation (41-43). Radial glial cells play a crucial role in the radial migration of neurons and are characterized by their astroglial properties and long radial processes (44). 
However, the impact of Reelin signaling on the cerebellar microglia is not clear during development. Previous studies revealed that microglia express Reelin receptors VLDL and ApoE2 (45-47). Evidence indicates that activation of ApoE2 and VLDL in microglia is associated with their improved ability to phagocytosis and clearance of apoptotic bodies (47-49). In our study, microglia of reeler, scrambler, and Apoe2 $2^{-/-}$mice showed no expression of FcgRs. A research by Bigler and colleagues showed that lipoproteins (namely low density lipoproteins) are the regulators of FcgR-mediated phagocytosis (50). In addition, another study showed that Dab1 is associated with phagocytic activity of macrophages/microglia (51). In our study, lack of LDL receptor family members (such as Apoe2) and their signaling downstream (Dab1) resulted in the lack of microglial FcgRs expression. Since phagocytic activity of microglia is important during cerebellar development, it is possible that manipulations of Reelin signaling affect microglial activity through ablation of FcgRs.

\section{Conclusion}

These results suggest a role for FcgRs in reelin signaling pathway, not related to Purkinje cell migration, but may be an adaptation to the environment with the large number of ectopic Purkinje cells.

\section{Declarations}

\section{ETHICAL APPROVAL AND CONSENT TO PARTICIPATE}

Not applicable.

\section{CONSENT FOR PUBLICATION}

Not applicable.

\section{AVAILABILITY OF DATA AND MATERIALS}

The article includes all the data used to support the conclusions.

\section{COMPETING INTERESTS}

The authors declare that they have no competing interests.

\section{FUNDING}

These studies were supported by grants from the Natural Sciences and Engineering Research Council (HM: NSERC Discovery Grant \# RGPIN-2018-06040), Thorlakson Foundation (HM: Grant \# 48205), and Children Hospital Research Institute of Manitoba (HM: Grant \# 320035).

\section{AUTHORS' CONTRIBUTIONS}


MRB (conducting experiment and writing manuscript), $\mathrm{XJ}$ (assisting in conducting experiment), AD (assisting in conducting experiment), SS (assisting in conducting experiment), SA (writing manuscript), SHC (editing manuscript), JK (editing manuscript), HM (editing manuscript and designing study).

\section{ACKNOWLEDGEMENTS}

Not applicable.

\section{AUTHORS' INFORMATION}

Maryam Rahimi Balaei (rahimibm@myumanitoba.ca), Xiaodan Jiao (jiaox3@myumanitoba.ca), Azadeh Dalvand (az.dalvand@gmail.com), Shahin Shabanipour (shabanis@myumanitoba.ca), Shayan Amiri (amiris@myumanitoba.ca), Seung H.Chung (chungsh@uic.edu), Jiming Kong (Jiming.Kong@umanitoba.ca), Hassan Marzban (Hassan.Marzban@umanitoba.ca).

\section{References}

1. Marzban H. Development of the Cerebellum from Molecular Aspects to Diseases: Springer; 2017.

2. Miyata T, Ono Y, Okamoto M, Masaoka M, Sakakibara A, Kawaguchi A, et al. Migration, early axonogenesis, and Reelin-dependent layer-forming behavior of early/posterior-born Purkinje cells in the developing mouse lateral cerebellum. Neural development. 2010;5(1):23.

3. Rahimi-Balaei M, Bergen H, Kong J, Marzban H. Neuronal Migration During Development of the Cerebellum. Frontiers in cellular neuroscience. 2018;12.

4. Larouche M, Beffert U, Herz J, Hawkes R. The Reelin receptors Apoer2 and VIdlr coordinate the patterning of Purkinje cell topography in the developing mouse cerebellum. PloS one. 2008;3(2):e1653.

5. Howell BW, Herrick TM, Cooper JA. Reelin-induced tryosine phosphorylation of disabled 1 during neuronal positioning. Genes \& development. 1999;13(6):643-8.

6. D'arcangelo G, Miao GG, Chen S-C, Scares HD, Morgan JI, Curran T. A protein related to extracellular matrix proteins deleted in the mouse mutant reeler. Nature. 1995;374(6524):719.

7. Howell BW, Hawkes R, Soriano P, Cooper JA. Neuronal position in the developing brain is regulated by mouse disabled-1. Nature. 1997;389(6652):733.

8. Trommsdorff M, Gotthardt M, Hiesberger T, Shelton J, Stockinger W, Nimpf J, et al. Reeler/Disabledlike disruption of neuronal migration in knockout mice lacking the VLDL receptor and ApoE receptor 2. Cell. 1999;97(6):689-701.

9. Bailey K, Balaei MR, Mehdizadeh M, Marzban H. Spatial and temporal expression of lysosomal acid phosphatase 2 (ACP2) reveals dynamic patterning of the mouse cerebellar cortex. The Cerebellum. 2013;12(6):870-81.

10. Mannan AU, Roussa E, Kraus C, Rickmann M, Maenner J, Nayernia K, et al. Mutation in the gene encoding lysosomal acid phosphatase (Acp2) causes cerebellum and skin malformation in mouse. 
Neurogenetics. 2004;5(4):229-38.

11. Frost JL, Schafer DP. Microglia: architects of the developing nervous system. Trends in cell biology. 2016;26(8):587-97.

12. Schafer DP, Stevens B. Microglia function in central nervous system development and plasticity. Cold Spring Harbor perspectives in biology. 2015;7(10):a020545.

13. Nakayama H, Abe M, Morimoto $C$, lida T, Okabe S, Sakimura K, et al. Microglia permit climbing fiber elimination by promoting GABAergic inhibition in the developing cerebellum. Nature communications. 2018;9.

14. Marın-Teva JL, Dusart I, Colin C, Gervais A, Van Rooijen N, Mallat M. Microglia promote the death of developing Purkinje cells. Neuron. 2004;41(4):535-47.

15. Quan Y, Möller T, Weinstein JR. Regulation of Fcy receptors and immunoglobulin G-mediated phagocytosis in mouse microglia. Neuroscience letters. 2009;464(1):29-33.

16. Okun E, Mattson MP, Arumugam TV. Involvement of Fc receptors in disorders of the central nervous system. Neuromolecular medicine. 2010;12(2):164-78.

17. Rahimi Balaei M, Jiao X, Ashtari N, Afsharinezhad P, Ghavami S, Marzban H. Cerebellar Expression of the Neurotrophin Receptor p75 in Naked-Ataxia Mutant Mouse. International journal of molecular sciences. 2016 Jan 15;17(1). PubMed PMID: 26784182. Pubmed Central PMCID: 4730356.

18. Bailey K, Balaei MR, Mannan A, Del Bigio MR, Marzban H. Purkinje cell compartmentation in the cerebellum of the lysosomal Acid phosphatase 2 mutant mouse (nax-naked-ataxia mutant mouse). PloS one. 2014;9(4):e94327.

19. Mariani J, Crepel F, Mikoshiba K, Changeux JP, Sotelo C. Anatomical, physiological and biochemical studies of the cerebellum from Reeler mutant mouse. Philosophical transactions of the Royal Society of London Series B, Biological sciences. 1977 Nov 2;281(978):1-28. PubMed PMID: 22882.

20. Rice DS, Curran T. Role of the reelin signaling pathway in central nervous system development. Annual review of neuroscience. 2001;24:1005-39. PubMed PMID: 11520926.

21. Sweet HO, Bronson RT, Johnson KR, Cook SA, Davisson MT. Scrambler, a new neurological mutation of the mouse with abnormalities of neuronal migration. Mammalian genome : official journal of the International Mammalian Genome Society. 1996 Nov;7(11):798-802. PubMed PMID: 8875886.

22. Goldowitz D, Cushing RC, Laywell E, D'Arcangelo G, Sheldon M, Sweet HO, et al. Cerebellar disorganization characteristic of reeler in scrambler mutant mice despite presence of reelin. The Journal of neuroscience : the official journal of the Society for Neuroscience. 1997 Nov 15;17(22):8767-77. PubMed PMID: 9348346.

23. Gallagher E, Howell BW, Soriano P, Cooper JA, Hawkes R. Cerebellar abnormalities in the disabled (mdab1-1) mouse. The Journal of comparative neurology. 1998 Dec 14;402(2):238-51. PubMed PMID: 9845246.

24. Ohsawa K, Imai Y, Sasaki Y, Kohsaka S. Microglia/macrophage-specific protein lba1 binds to fimbrin and enhances its actin-bundling activity. Journal of neurochemistry. 2004 Feb;88(4):844-56. PubMed PMID: 14756805. Epub 2004/02/06. eng. 
25. Weruaga E, Alonso JR, Porteros A, Crespo C, Arevalo R, Brinon JG, et al. Nonspecific labeling of myelin with secondary antisera and high concentrations of Triton X-100. The journal of histochemistry and cytochemistry : official journal of the Histochemistry Society. 1998 Jan;46(1):109-18. PubMed PMID: 9405500.

26. Afshar P, Ashtari N, Jiao X, Rahimi-Balaei M, Zhang X, Yaganeh B, et al. Overexpression of Human SOD1 Leads to Discrete Defects in the Cerebellar Architecture in the Mouse. Frontiers in neuroanatomy. 2017;11:22. PubMed PMID: 28424594. Pubmed Central PMCID: 5372795.

27. Bailey K, Rahimi Balaei M, Mehdizadeh M, Marzban H. Spatial and temporal expression of lysosomal acid phosphatase 2 (ACP2) reveals dynamic patterning of the mouse cerebellar cortex. Cerebellum. 2013 Dec;12(6):870-81. PubMed PMID: 23780826.

28. Hazama GI, Yasuhara O, Morita H, Aimi Y, Tooyama I, Kimura H. Mouse brain IgG-like immunoreactivity: strain-specific occurrence in microglia and biochemical identification of IgG. The Journal of comparative neurology. 2005 Nov 14;492(2):234-49. PubMed PMID: 16196032.

29. Ito D, Imai Y, Ohsawa K, Nakajima K, Fukuuchi Y, Kohsaka S. Microglia-specific localisation of a novel calcium binding protein, Iba1. Brain research Molecular brain research. 1998 Jun 1;57(1):1-9. PubMed PMID: 9630473.

30. Suchorukova EG, Kirik OV, Korzhevskii DE. The use of immunohistochemical method for detection of brain microglia in paraffin sections. Bulletin of experimental biology and medicine. 2010 Nov;149(6):768-70. PubMed PMID: 21165442.

31. Shapiro LA, Wang L, Ribak CE. Rapid astrocyte and microglial activation following pilocarpineinduced seizures in rats. Epilepsia. 2008;49 Suppl 2:33-41. PubMed PMID: 18226170.

32. Rahimi-Balaei M, Jiao X, Shabanipour S, Dixit R, Schuurmans C, Marzban H. Zebrin II Is Ectopically Expressed in Microglia in the Cerebellum of Neurogenin 2 Null Mice. Cerebellum. 2019 Feb;18(1):5666. PubMed PMID: 29909450.

33. Upender M, Dunn J, Wilson S, Naegele J. Immunoglobulin molecules are present in early-generated neuronal populations in the rat cerebral cortex and retina. Journal of Comparative Neurology. 1997;384(2):271-82.

34. Niu N, Zhang J, Guo Y, Zhao Y, Korteweg C, Gu J. Expression and distribution of immunoglobulin G and its receptors in the human nervous system. The international journal of biochemistry \& cell biology. 2011;43(4):556-63.

35. Ashwell K. Microglia and cell death in the developing mouse cerebellum. Developmental Brain Research. 1990;55(2):219-30.

36. Meier P, Finch A, Evan G. Apoptosis in development. Nature. 2000;407(6805):796.

37. Yeo W, Gautier J. Early neural cell death: dying to become neurons. Developmental biology. 2004;274(2):233-44.

38. Bilimoria PM, Stevens B. Microglia function during brain development: new insights from animal models. Brain research. 2015;1617:7-17. 
39. Song X, Tanaka S, Cox D, Lee SC. Fcy receptor signaling in primary human microglia: differential roles of PI-3K and Ras/ERK MAPK pathways in phagocytosis and chemokine induction. Journal of leukocyte biology. 2004;75(6):1147-55.

40. Ueyama T, Lennartz MR, Noda Y, Kobayashi T, Shirai Y, Rikitake K, et al. Superoxide production at phagosomal cup/phagosome through $\beta$ I protein kinase $\mathrm{C}$ during FcyR-mediated phagocytosis in microglia. The Journal of Immunology. 2004;173(7):4582-9.

41. Hartfuss E, Förster E, Bock HH, Hack MA, Leprince $P$, Luque JM, et al. Reelin signaling directly affects radial glia morphology and biochemical maturation. Development. 2003;130(19):4597-609.

42. Förster E, Tielsch A, Saum B, Weiss KH, Johanssen C, Graus-Porta D, et al. Reelin, Disabled 1, and $\beta 1$ integrins are required for the formation of the radial glial scaffold in the hippocampus. Proceedings of the National Academy of Sciences. 2002;99(20):13178-83.

43. Weiss $\mathrm{KH}$, Johanssen $\mathrm{C}$, Tielsch A, Herz J, Deller T, Frotscher $\mathrm{M}$, et al. Malformation of the radial glial scaffold in the dentate gyrus of reeler mice, scrambler mice, and ApoER2/VLDLR-deficient mice. Journal of Comparative Neurology. 2003;460(1):56-65.

44. Campbell K, Götz M. Radial glia: multi-purpose cells for vertebrate brain development. Trends in neurosciences. 2002;25(5):235-8.

45. Laskowitz D, Thekdi A, Thekdi S, Han S, Myers J, Pizzo S, et al. Downregulation of microglial activation by apolipoprotein $E$ and apoE-mimetic peptides. Experimental neurology. 2001;167(1):7485.

46. Jiang Q, Lee CD, Mandrekar S, Wilkinson B, Cramer P, Zelcer N, et al. ApoE promotes the proteolytic degradation of $A \beta$. Neuron. 2008;58(5):681-93.

47. Christie RH, Chung H, Rebeck GW, Strickland D, Hyman BT. Expression of the very low-density lipoprotein receptor (VLDL-r), an apolipoprotein-E receptor, in the central nervous system and in Alzheimer's disease. Journal of neuropathology and experimental neurology. 1996;55(4):491-8.

48. Grainger DJ, Reckless J, McKilligin E. Apolipoprotein E modulates clearance of apoptotic bodies in vitro and in vivo, resulting in a systemic proinflammatory state in apolipoprotein E-deficient mice. The Journal of Immunology. 2004;173(10):6366-75.

49. Yin B, Loike JD, Kako Y, Weinstock PH, Breslow JL, Silverstein SC, et al. Lipoprotein lipase regulates Fc receptor-mediated phagocytosis by macrophages maintained in glucose-deficient medium. The Journal of clinical investigation. 1997;100(3):649-57.

50. Bigler RD, Khoo M, Lund-Katz S, Scerbo L, Esfahani M. Identification of low density lipoprotein as a regulator of Fc receptor-mediated phagocytosis. Proceedings of the National Academy of Sciences. 1990;87(13):4981-5.

51. Trommsdorff M, Borg J-P, Margolis B, Herz J. Interaction of cytosolic adaptor proteins with neuronal apolipoprotein $\mathrm{E}$ receptors and the amyloid precursor protein. Journal of Biological Chemistry. 1998;273(50):33556-60.

\section{Figures}




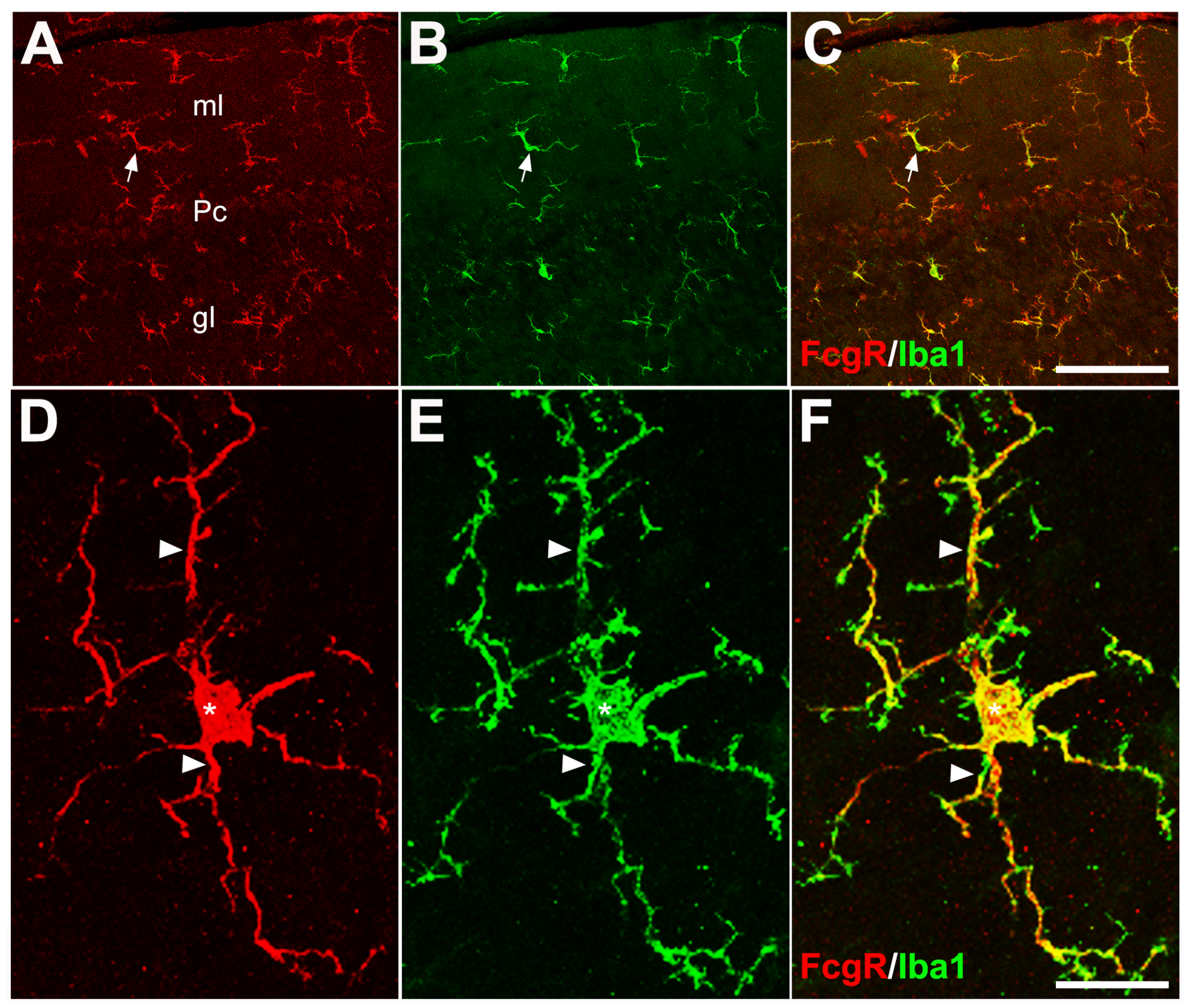

Figure 2

The expression of FcgR in the adult mouse cerebellum. A, B, C. Double immunofluorescence staining for FcgRs (A - red) and Iba1 (B - green; C - merged) of a transverse section at adult mouse cerebellum showing the microglia (arrows) that scattered in non-overlapping manner in the molecular layer ( $\mathrm{ml}$ ), Purkinje cell layer (Pcl), and granular layer (gl). D, E, F: A high magnification view of the microglia double immunofluorescence staining for FcgR receptor (D - red) and Iba1 (E - green; F - merged) showing detail of FcgR distribution on microglial cell body (asterisks) and branches (arrowheads) which are co-labeled with Iba1. Scale bars: $100 \mu \mathrm{m}$ (C applies to A, B); $25 \mu \mathrm{m}$ (F applies to D, E) . 


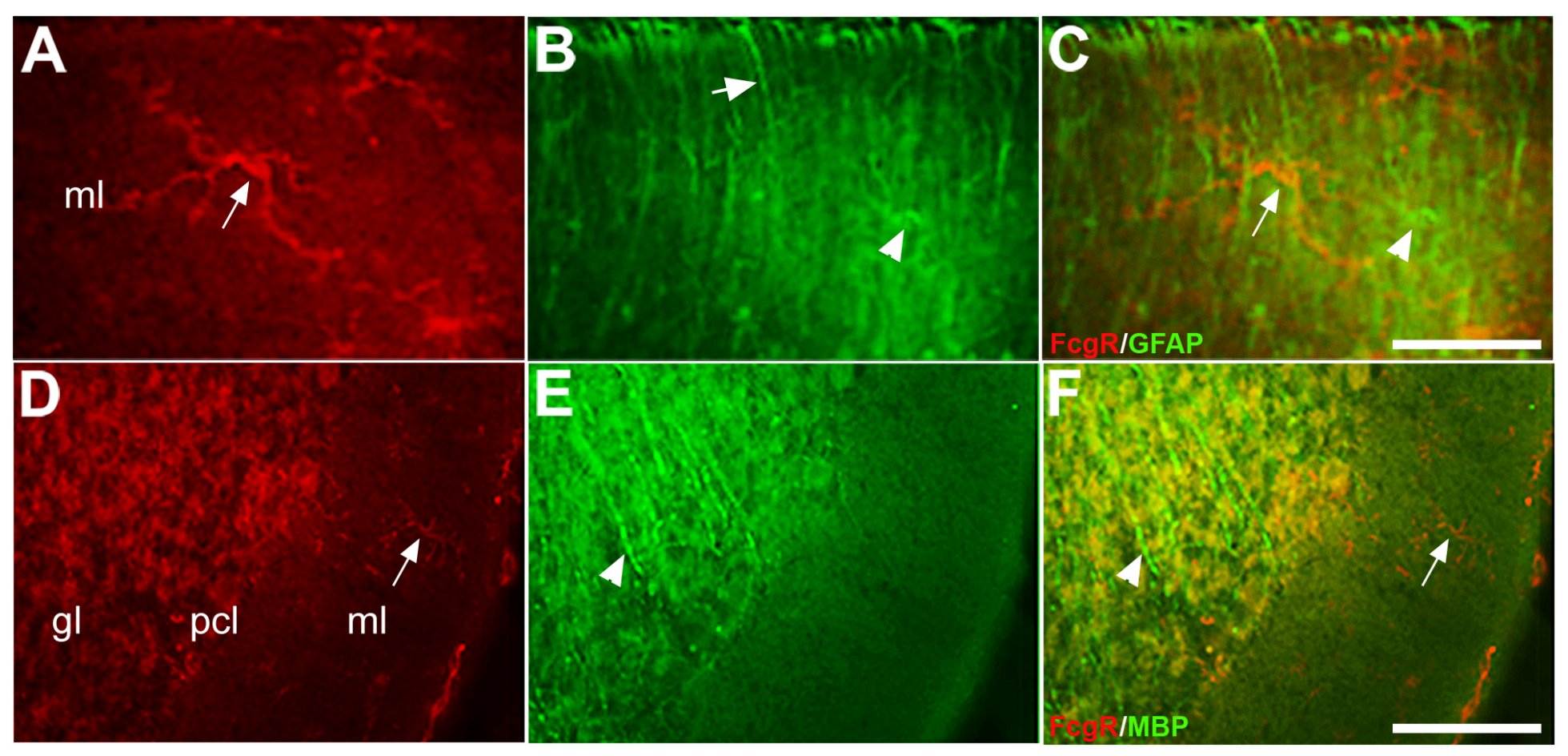

\section{Figure 3}

Double immunofluorescence-stained transverse sections through the adult cerebellum to show the FcgR expression and GFAP and MBP expression in astrocytes and oligodendrocytes. A, B, C. Double immunofluorescence staining of the cerebellum for anti FcgR ( $A$ - red) and GFAP (B - red; $C$ - merged) shows that the FcgR+ cell (arrow) in molecular layer and GFAP+ astrocytes (B - arrowhead) and Bergmann Glial fibers (B - arrow) in molecular layer $(\mathrm{ml})$ which are not co-labeled with FcgR+ microglia (C - arrow and arrowhead). D, E, F. Double immunofluorescence staining of the cerebellum for anti FcgR $(A-$ red) and MBP (B - red; $C$ - merged) shows that the FcgR+ cells in cerebellar cortex and indicated by arrow in molecular layer and strong MBP immunoreactivity in granular layer ( $\mathrm{gl}$ ) ( $\mathrm{E}$ - arrowhead) which are not co-labeled with $\mathrm{FcgR}+$ microglia ( $\mathrm{F}-$ arrow indicates microglia in the molecular layer $(\mathrm{ml})$ ). Scale bars: $50 \mu \mathrm{m}$ (C applies to A, B); $100 \mu \mathrm{m}$ ( $F$ applies to D, E). 


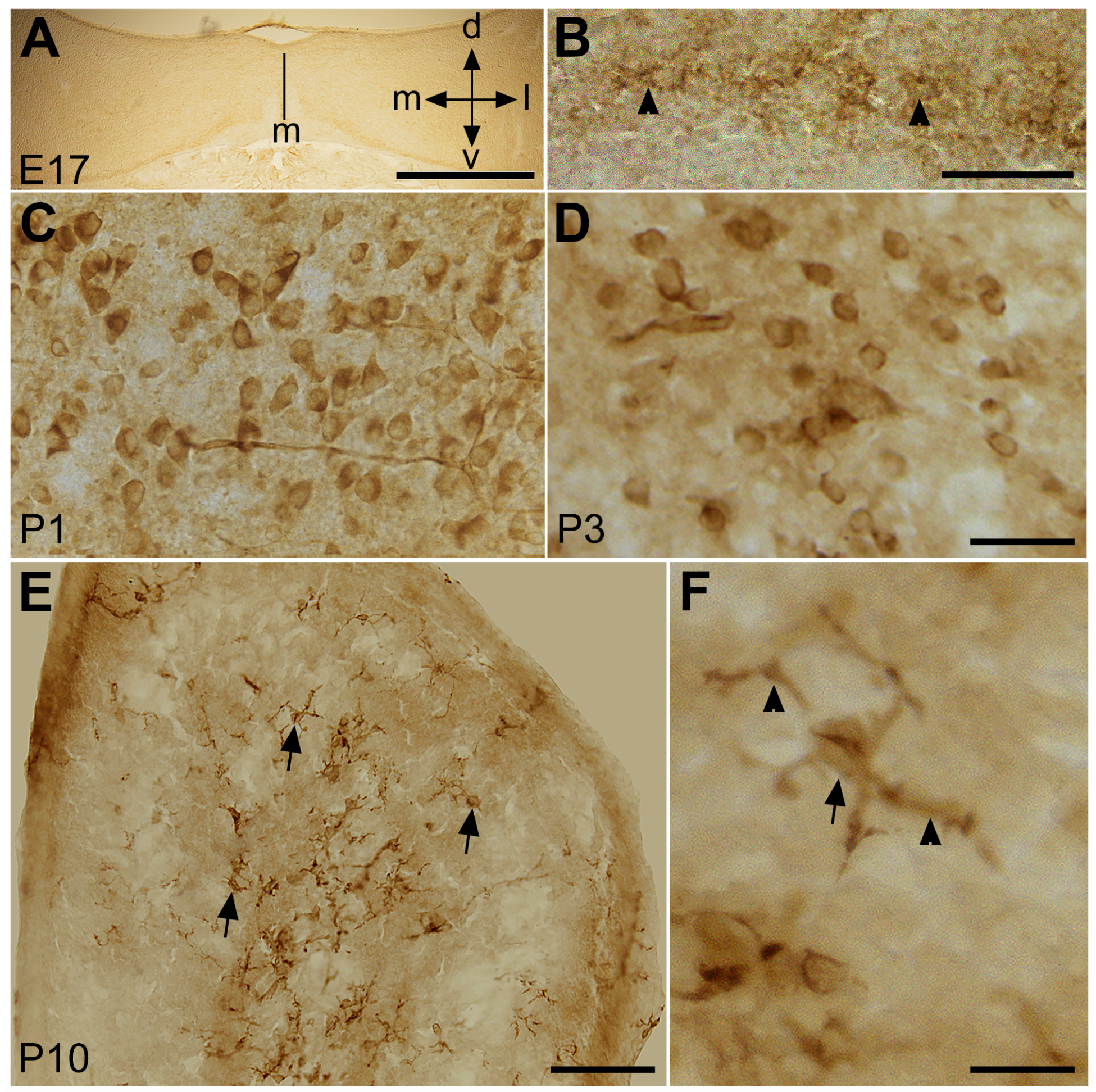

\section{Figure 6}

Peroxidase immunostaining of the cerebellar sections to show the development of the FcgR+ cells. A, B, C, D. FcgRs immunoperoxidase staining of a frontal section through the cerebellar at E17 showing weak immunoreactivity at the cerebellar core that is indicated in a higher magnification view of the same section by the arrowhead in " $\mathrm{B}$ ". FcgR immunoperoxidase reactivity is strongly outlined microglial cell body at P1 (C) and P3 (D). E, F. FcgR immunoperoxidase staining of a sagittal section through the cerebellum at P10 shows strong immunoreactivity in microglia (e.g. arrow) in white matter and scattered 
in cerebellar cortex. F) A higher magnification view of the same "E" shows microglial cell body (arrow) and developing branches of the microglial indicated by arrowhead. Scale bars: $1 \mathrm{~mm}(A) ; 250 \mu \mathrm{m}(B)$; $50 \mu \mathrm{m}$ (D applies to C); $100 \mu \mathrm{m}(\mathrm{E}) ; 25 \mu \mathrm{m}(\mathrm{F})$.

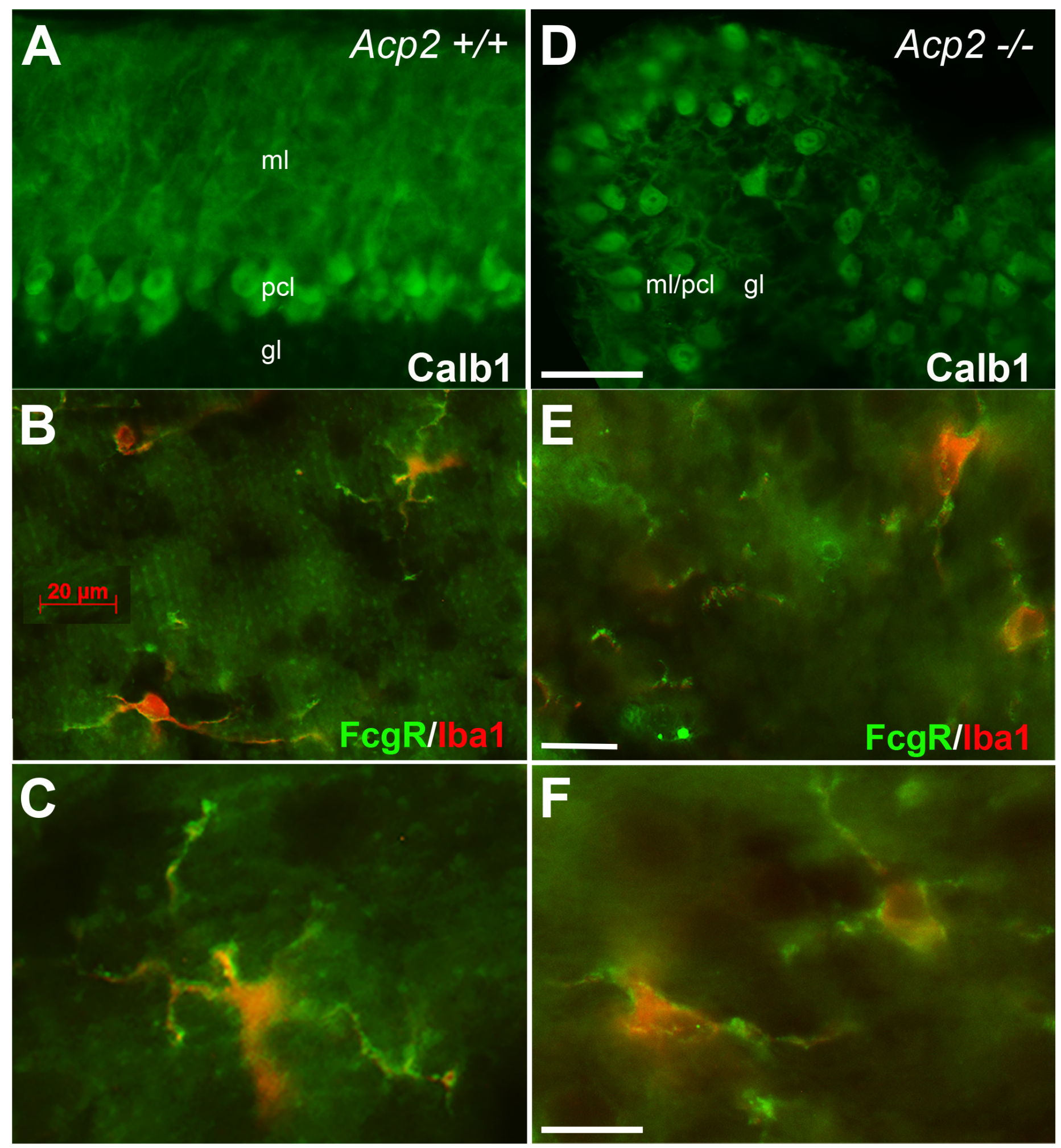

\section{Figure 8}

Transverse section of Acp2-/- and wt cerebellum, immunostained with Calb1 at P17 and FcgR/lba1 at P21. A, D. Immunostaining of wild type mouse at P17 showing the Purkinje cell bodies form a monolayer 
with their dendritic arborization in molecular layer $(\mathrm{ml})$ that is directed toward pia mater, while in Acp2-/Purkinje cell bodies are invaded in $\mathrm{ml}$ and form a multilayer of the cells and dendrites are less developed with multidirectional in $\mathrm{ml}$. B, C, E, F. Frontal section of Acp2-/- and wt cerebellum, immunostained with anti- FcgR (green) and Iba1 (red) at P21 shows a co-localization of FcgR and Iba1 in microglia in wt (B, C) and $A c p 2-/-(E, F)$. A high magnification view of the microglia in $C$ and $F$ from $B$ and $E$, respectively. Scale bars: $100 \mu \mathrm{m}$ (D applies to A); $20 \mu \mathrm{m}$ (E applies to B); $25 \mu \mathrm{m}$ (F applies to C).

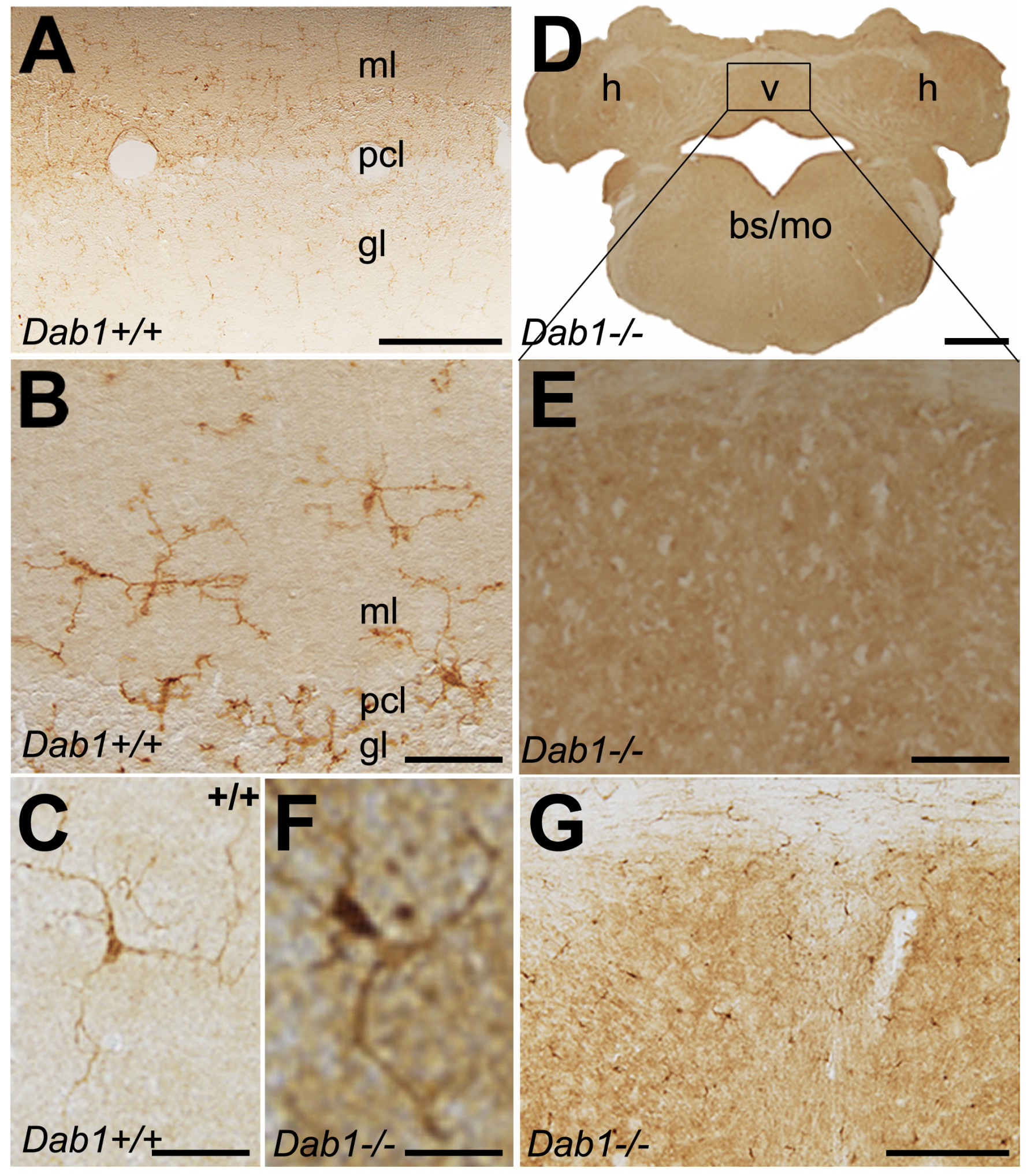

Figure 9 
Transverse section of adult scm (Dab1-/-) and wt cerebellum, immunostained for FcgR/lba1. A, B, C. transverse section of the wt cerebellum immunostained with FcgR shows microglia scattered in cerebellar cortex (A), and higher magnification shows the microglia distribution, cell bodies and branches in " $B$ " and "C". D, E, F, G. Transverse section through the scm (Dab1-/-) cerebellum and brain stem/medulla oblognta (bs/mo) immunostained with anti FcgR showing no positive immunoreactivity in the cerebellum and mo (D), clearly shows in high magnification (E). Transverse section of scm (Dab1-/-) cerebellum immunostained with Iba1 showing the presence of microglia in cerebellar cortex $(\mathrm{G})$ and higher magnification (F). Scale bars: $250 \mu \mathrm{m}$ (A and G); $50 \mu \mathrm{m}$ (B and E); $25 \mu \mathrm{m}$ (C and F); $1 \mathrm{~mm}(\mathrm{D})$. 


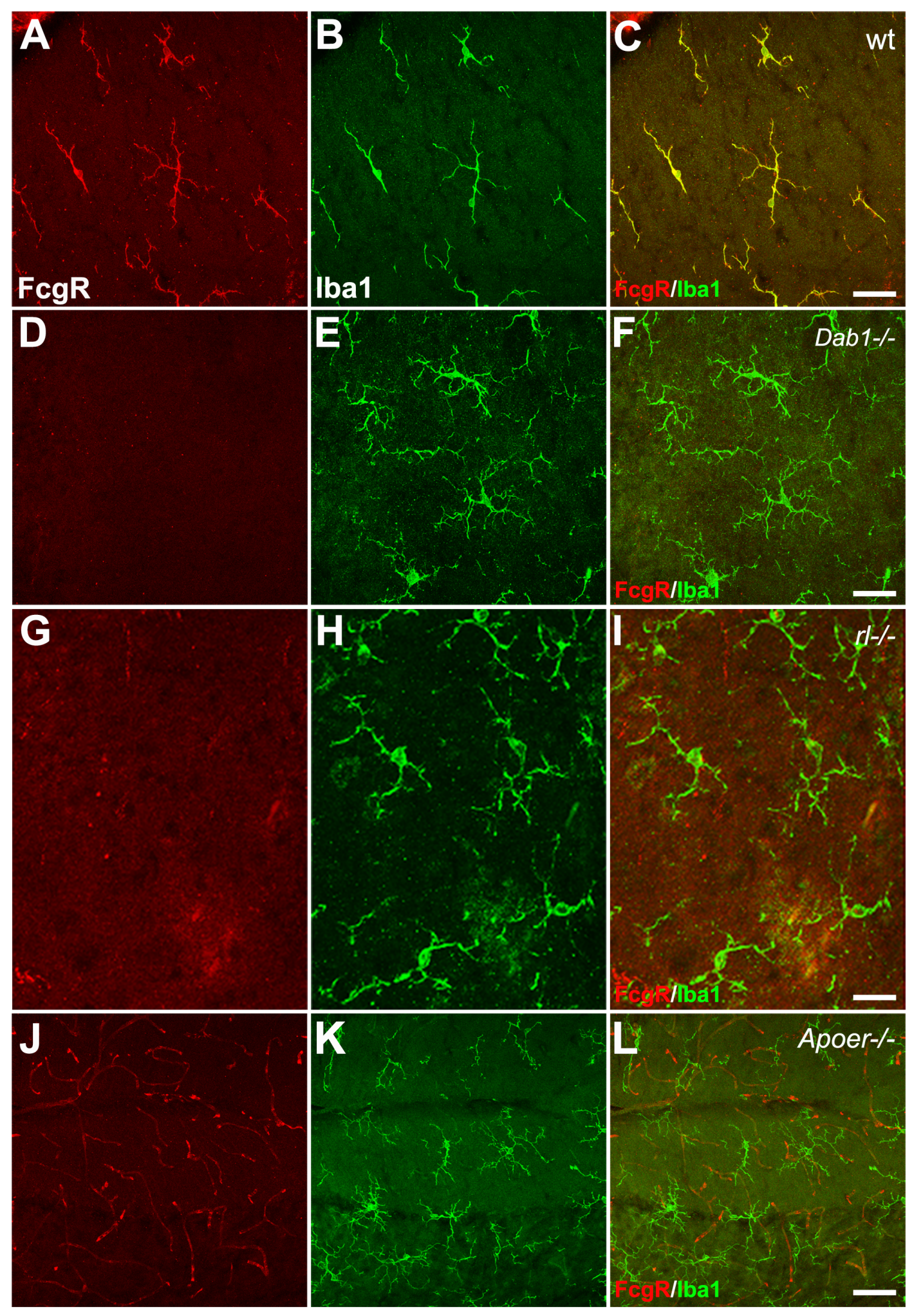

\section{Figure 11}

Transverse sections of wild type, scm (Dab1-/-), reeler (rl-/-), Apoer -/- cerebella immunostained with antiFcgRs and anti-lba1. A, B, C. Transverse sections of wild type cerebellum immunostained with anti- FcgRs (A-red) and anti-lba1 (B-green; C - merged) showing FcgR and Iba1 co-localization on microglia. D, E, F. Transverse sections of scm (Dab1-/-) cerebellum double immunostained with anti- FcgRs (D - red) and anti-Iba1 (E - green; F - merged) showing that FcgR is not expressed in microglia which are present and 
express Iba1. G, H, I. Transverse sections of reeler (rl-/-) cerebellum double immunostained with antiFcgRs ( $\mathrm{G}$ - red) and anti-lba1 ( $\mathrm{H}$ - green; I - merged) showing that FcgR is not expressed in microglia which are present and express Iba1. J, K, L. Transverse sections of Apoer -/- cerebellum double immunostained with anti- FcgRs ( $\mathrm{J}$ - red) and anti-lba1 ( $\mathrm{K}$ - green; $\mathrm{L}$ - merged) showing that FcgR is not expressed in microglia which are present and express Iba1. Scale bars: $40 \mu \mathrm{m}$ (C applies to A, B and $\mathrm{L}$ applies to J, K); $25 \mu \mathrm{m}$ (F applies to D, E); $20 \mu \mathrm{m}$ (I apply to $G, H$ ). 